\title{
FRANCISCO DE LEON, PINTOR DEL SIGLO XVII
}

\author{
P OR
}

\author{
LEOPOLDO I. ORENDÁ N
}

ON DE tal manera escasas las noticias referentes a los pintores que - florecieron en la Nueva Galicia y a sus obras, que se podría pensar que no hubo quienes ejercitaron tal oficio. La aparente carencia de profesionales en esa rama artística, es imputable exclusivamente al desconocimiento de las actividades desplegadas por aquel entonces $y$, también, a que faltaron individuos de méritos relevados, capaces de legarnos sus nombrea, aparejados a la fama de sus obras, como es el caso de José de Ibarra, nativo de Guadalajara, según investigaciones relativamente recientes.

Desgraciadamente los manantiales de referencia y orientaciones, como podían ser los archivos de los monasterios, libros de cuentas, etc., se dispersaron cuando no fueron destruidos. Por otra parte, la sistemática manía persecutoria, unida a los atentados de todo género perpretrados en años y años, causaron irreparables estragos. Ias colecciones pictóricas se disgregaron yendo a parar sus componentes a manos de particulares unos, otros salieron del pais, algo varió de radicación, y mucho, lamentablemente, quedó aniquilado a causa del abandono y de la incuria. 
No obstante estos males, eran tantas las obras de arte que ornaban los muros de las iglesias y los establecimientos religiosos, sitios en donde tuvieron preferente acogida, que de ellas algo queda, y con estos restos, puede colegirse y trabarse cierta unidad para sacar a luz incógnitos autores, y medio catalogar las producciones.

Por lo que concierne a la vida de los ejecutantes es labor reservada para los desentrañadores de secretos, qué añejos papeles contengan, lo cual puede acontecer, pues hay veneros inexplorados $y$ otros, andan rodando por sitios no imaginados.

Entre los artífices casi ignorados se encuentra Francisco de León. Cabe conjeturar que fué tapatio, aun cuando no tenemos algo escrito para fundar esta aseveración, aduciéndola porque en Jalisco y Estados limítrofes son conocidas sus producciones y no en otras partes. En la ciudad de México y sus aledaños en donde más cuidadosamente se han practicado investigaciones y estudios sobre las manifestaciones artísticas de todo género del período colonial, pasa inadvertido, mencionándose exclusivamente dos de sus pinturas. Una, ya desaparecida, engalanó la escalera del noviciado de Santo Domingo en México y representaba La Gloria de la Virgen del Rosario, la cual ahora se cataloga, porque así lo dijo don Bernardo Couto en el siglo próximo pasado, calificándola de "valiente". Otra, La huida a Egipto, perteneciente a la colección Franz Mayer, la que comenta el señor Velázquez Chávez en su obra Tres siglos de piniura colonial, diciendo que la reproduce, "por su interés pictórico y su valor en la historia de nuestras artes plásticas". Don Manuel Toussaint, en su Arte colonial de México, cita, de una colección particular, "una pequeña tabla con la Purísima rodeada de ángeles".

De León vivió en la segunda mitad del siglo xvir. Afirma Couto que el cuadro del monasterio de Santo Domingo era del año de 1727, pormenor que a nuestro juicio debe estar equivocado porque existe una pintura, a la que aludiremos, datada en 1670 , que denota ser factura de un artista ya cuajado, pareciendo poco probable que cincuenta y siete años después se lanzara a hacer la composición perdida. Todas sus pinturas hasta la fecha localizadas, menos una, carecen del año de manufactura, mas al examinarlas no desmienten en múltiples detalles que vienen de aquellos tiempos.

Digno es de mencionarse, en primer término, un óleo que muestra La muerte de San Francisco Javier, que está en la sacristía de la basilica de Zapopan. El santo exhala el último suspiro en la desierta isla de San- 
cia guarecido debajo de un mal forjado cobertizo de ramas. A la izquierda hay un fondo de mar, tema muy raro en las pinturas coloniales. En el agua se mecen dos galeones de altos bordos, con sus velas desplegadas y las grímpolas agitadas por el viento, lanzando los cañones del puente superior, fuego por sus bocas. En un rompimiento de gloria, siete querubines de agradables rostros, parecen aguardar el fin terrenal del misionero.

Tiene de muy interesante esta pintura las figuras, seguramente retratos, de dos pequeñas niñas arrodilladas en los ángulos inferiores. Por los precisos detalles de su indumentaria, y por la actiud encantadora de las expresiones, denotan que el artista las trabajó con cariño. A este respecto hay una circunstancia digna de tomarse en consideración. En el Museo de Guadalajara se conserva un lienzo que vino de la Academia de San Carlos, firmado por Juan Rodríguez Juátez fechado en 1720 , en el cual se ven como oferentes a dos niñas - Uribe Casteyón y Sandoval- muy similares por su colocación, a las pintadas por De León. ¿ No cabría suponer que éste hubiera aprendido en el taller de Antonio Rodríguez, padre de Rodríguez Juárez? Todo se mueve alrededor de fechas próximas y de estilos semejantes. Por cierto que estas encantadoras niñas de De León, con las de los pintores del siglo xvir, forman un interesante conjunto de retratos que hay que tener en cuenta como antecedente de los grandes retratistas mexicanos no académicos del siglo xix.

En el claustro bajo del convento zapopano existe otro cuadro $E l$ bautismo de Jesucristo. Independientemente de las imágenes principales, motivo de la composición, Jesucristo y el Bautista, se ven dos arcángeles de ensortijados cabellos, que guardan las vestiduras del Señor. De la parte media superior desciende el Espíritu Santo en forma de paloma. Mas en lo alto, el Padre Eeterno con dos ángeles a sus lados que sostienen ramos de flores, quedan cortados por una filacteria que lleva escrito el texto del versículo xvir del capítulo in del Evangelio de San Marcos, denotanda al pintor como hábil letrerista. La composición está flanqueada por árboles de espeso follaje, en donde, multicolores pajarillos imprimen la nota candorosa. EI fondo de este cuadro parece un remedo de los paisajes de Echave, guardando la proporción: un caudaloso río se desliza en medio de los bosques de tupida vegetación intensamente verde $y$ se desprenden en cascadas. 
En las dos pinturas descritas, De León puso su nombre rubricándolo al estilo de la época, rasgueando cual si lo estampara con la pluma en un papel.

La parroquia de Chapala adorna la pared del fondo de su sacristía con un óleo donado hace algunos años por el señor Witter Bynner, que mide $1.96 \times 1.30 \mathrm{~m}$, pintado por De León, a devoción de Juan Cornejo. Representa $E l$ Calvario y contiene las figuras de Nuestro Señor, la Virgen, San Juan y la Magdalena, todas con las actitudes y colorido habituales en la imaginería mexicana. Este cuadro nada dice, hallándose además estropeado por culpa de quien buscó mejorarlo remendando, no restaurando, las partes perdidas por efectos del tiempo, obteniendo como resultado, afear la caja del cuerpo del crucificado, y los brazos y manos de la Magdalena.

El Museo de Guadalajara expone una Virgen al pie de la Cruz, catalogada y firmada por el mismo artista. La imagen se manifiesta con una descomunal espada clavada en el pecho, sosteniendo entre las manos, la corona de espinas.

Una de las oficinas de la catedral de Guadalajara luce, eri marco de la época, un San Francisco de Sales (2.30 × $1.45 \mathrm{~m}$.), imagen que se halla de pie ante un pequefio altar orando con un frontal bordado con escudos heráldicos de color verde. Sobre él se ven un crucifijo, una plateada campanilla y dos libros, las obras cumbres del fundador de la visitación: La introducción a la vida devota y el Tratado dal amor de Dios. De la parte superior izquierda, baja el Espíritu Santo en figura de paloma, y flota una bola de fuego despidiendo llamas, atributo de San Francisco de Sales en la iconografía religiosa. El personaje está ataviado con sotana gris, sobrepelliz blanco calado, y muceta azulada. Del lado opuesto se desprende una cortina roja en pliegues recogidos por moteados cordones.

Fuera de Jalisco, en la capital de Aguascalientes, hay una tabla en la que se simboliza a la Virgen y a San José pidiendo posada; se supone la víspera de Navidad, $y$ que según se tienen informes es, o era, propiedad del presbitero don Wenceslao Romo. Además se halla, en manos de don Fernando Juárez Frlas, de la ciudad de Zacatecas, un bleo que representa a Santa Rita vestida con su negro hábito de agustina, hincada ent actitud de arrobamiento ante un altarcillo ornamentado con dos candeleros con sus velas encendidas en honor de una imagen de Jesús crucificado, coronada por un dosel rojo con flecos y caída de paños muy similares a las telas del cuadro de San Francisco de Sales de la catedral 
de Guadalajara, como también es la técnica de los frontales y la del Cristo, en ambas composiciones. Al fondo de la escena una ventana da vista a las copas de unos árboles y un complemento de nubes. En primer término, a la derecha, sobre un banquillo puso el artista una calavera, un higo y algo, al parecer, como una concha. Apoyado en las patas delanteras del banco está un libro abierto; inicia el texto gran capitular, seguida de signos con todas las características de la escritura del siglo xvir. Debajo del libro el pintor estampó su firma: Leon fat. Pinx Año de 1670 , con la circunstancia de que el rasgo vertical de la letra efe lo prolongó en rúbrica de idéntica forma como signó los cuadros de Zapopan.

Para corroborar la suposición de que De León tuvo su taller en Guadalajara, consideramos, bastan las obras nombradas, conservándose en su mayoría en los primitivos lugares para donde fueron hechas. Las que andan fuera, como son propiedad de particulares, posiblemente tienen eI mismo origen; nada menos, hace poco tiempo, un traficante de antigiedades vendió un Santo Domingo de Guzmán, cuyo paradero se ignora.

Como conclusión, es de interés referir que en el templo de San Francisco de la capital tapatia existían dos pinturas del mismo autor, las que fueron pasto del fuego cuando manos criminales incendiaron en 1936 tan venerable lugar. 


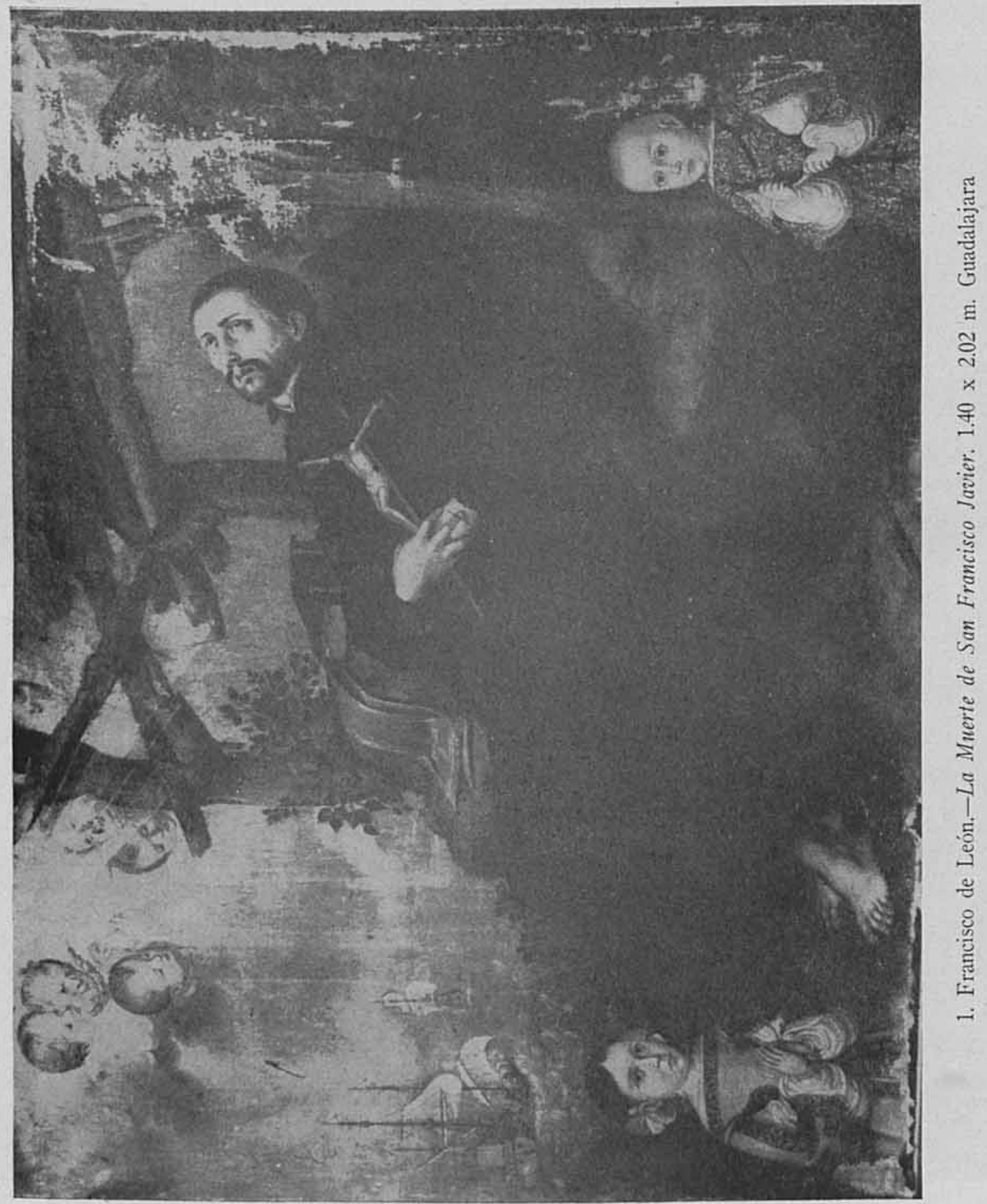




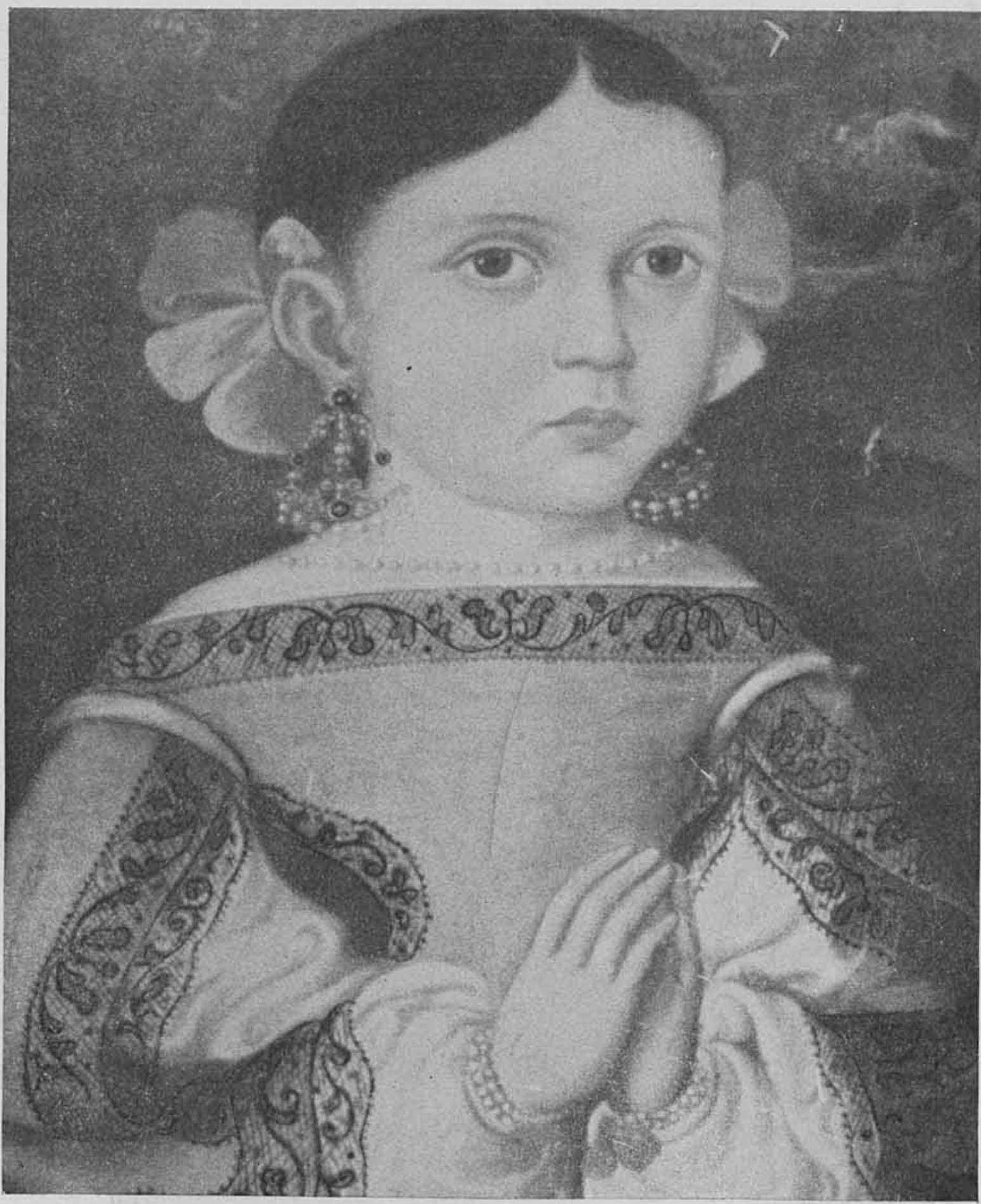

2. Francisco de León.-La Muerte de San Francisco Javier. Detalle. Niña orante. 


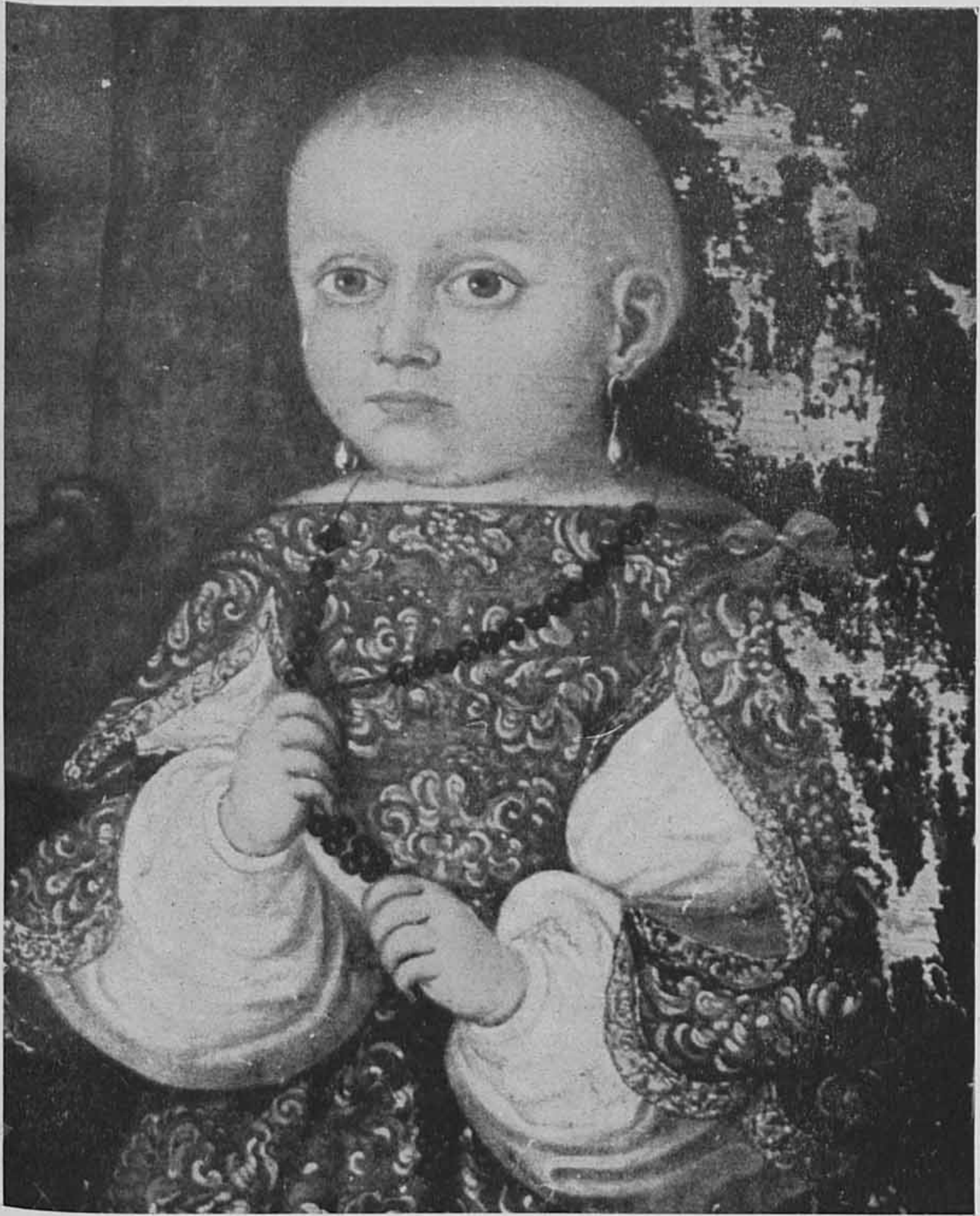

3. Francisco de León.-La Muerte de San Francisco Jazier. Detalle 


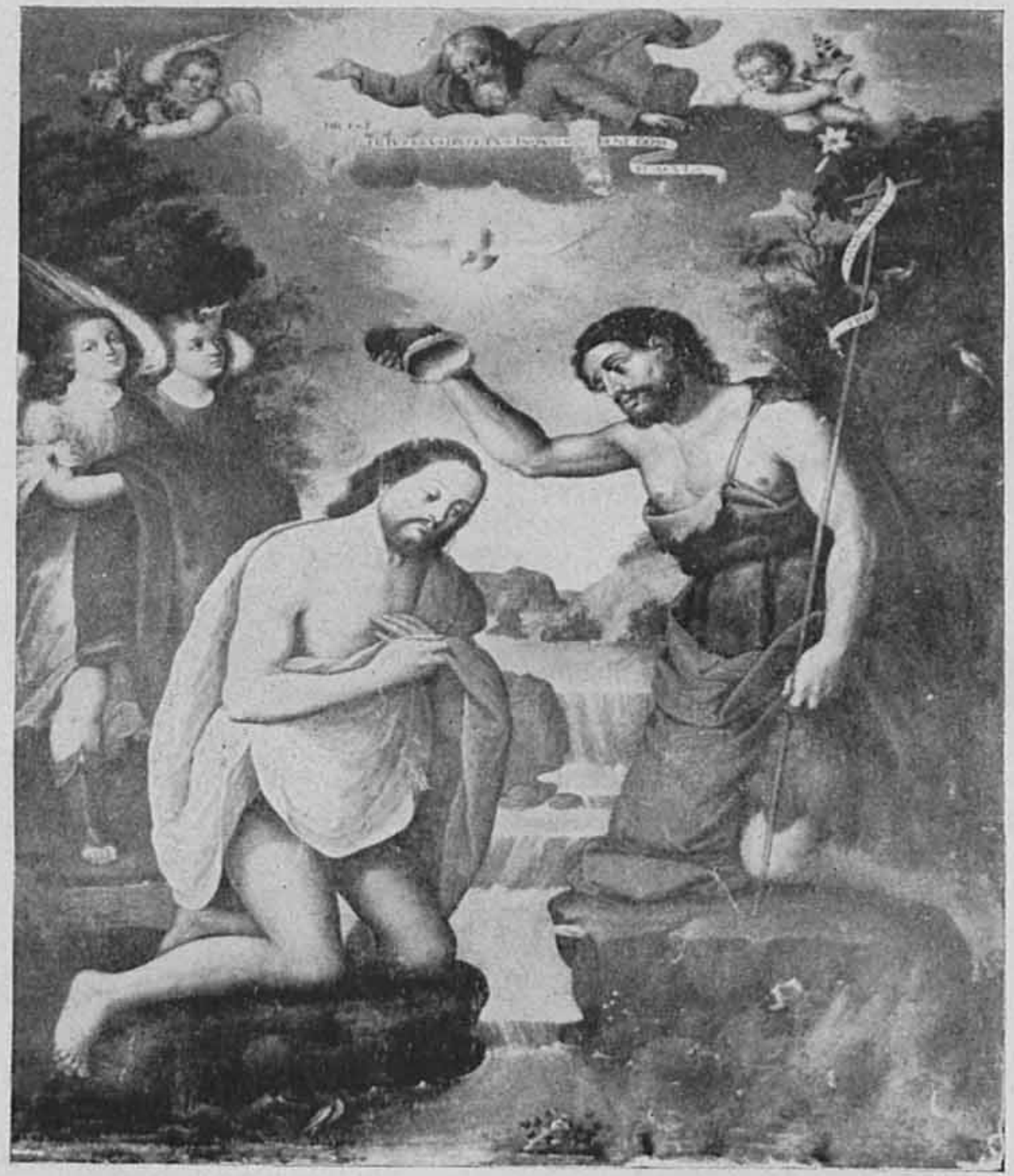

4. Francisco de León.-Bautismo de Cristo. $1.42 \times 2.02 \mathrm{~m}$. Zapopan, Guadalajara 


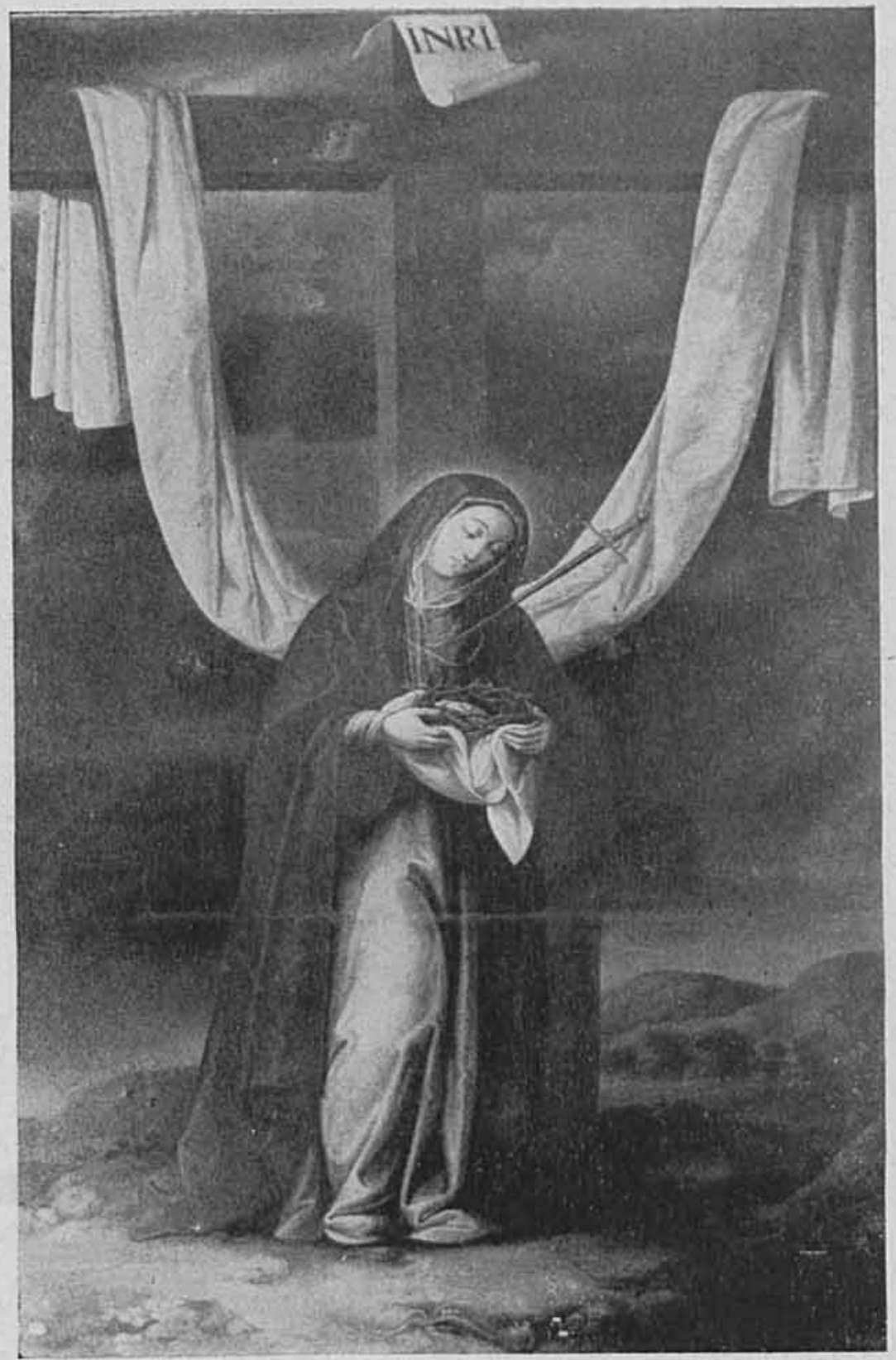

5. Francisco de León.-Virgen al Pie de la Crus. $1.85 \times 1.60 \mathrm{~m}$. Guadalajara 
DOI: http://dx.doi.org/10.22201/iie.18703062e.1949.17.473

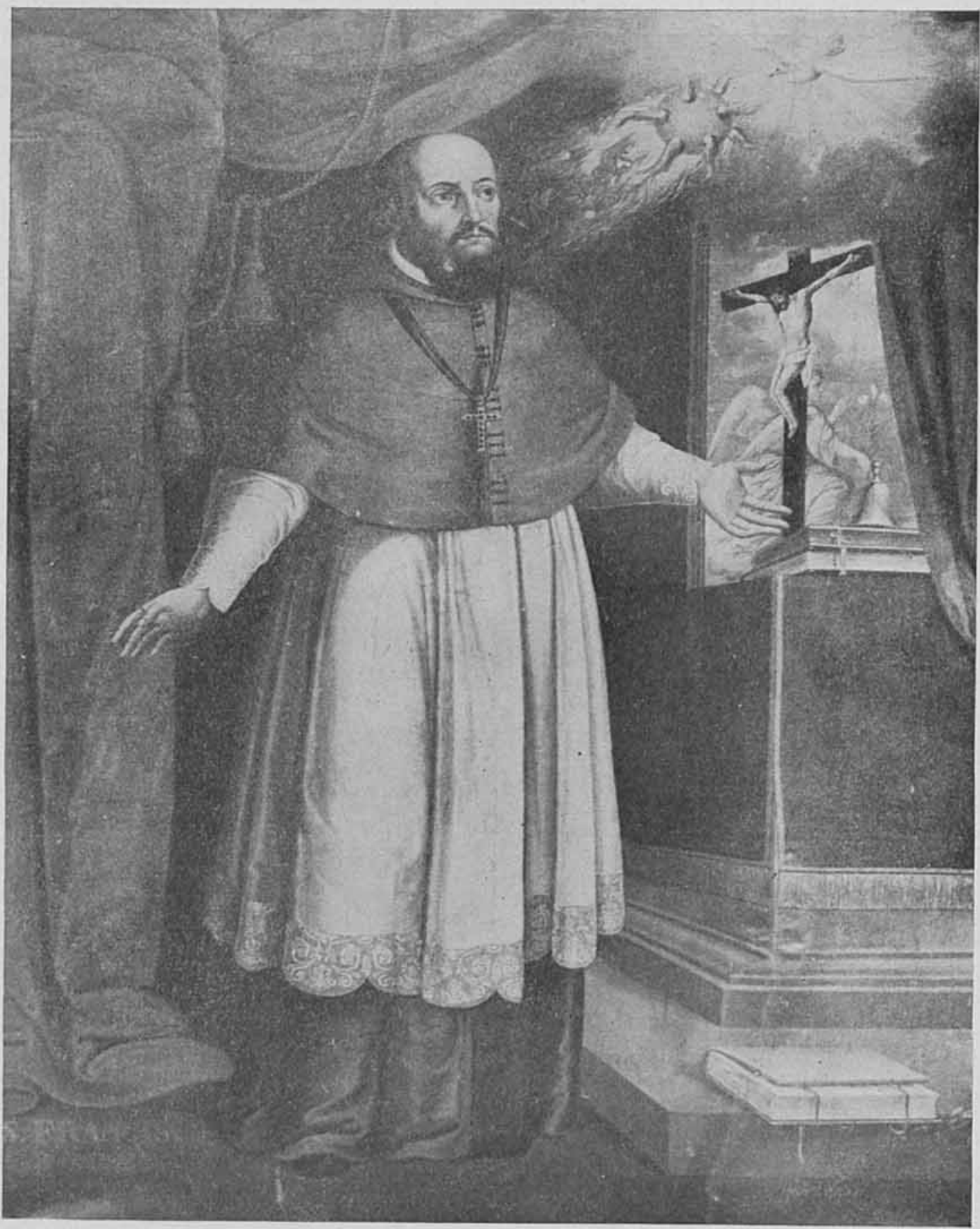

6. Francisco de León.-San Francisco de Sales. 2.03 x 1.45 m. Guadalajara 
DOI: http://dx.doi.org/10.22201/iie.18703062e.1949.17.473

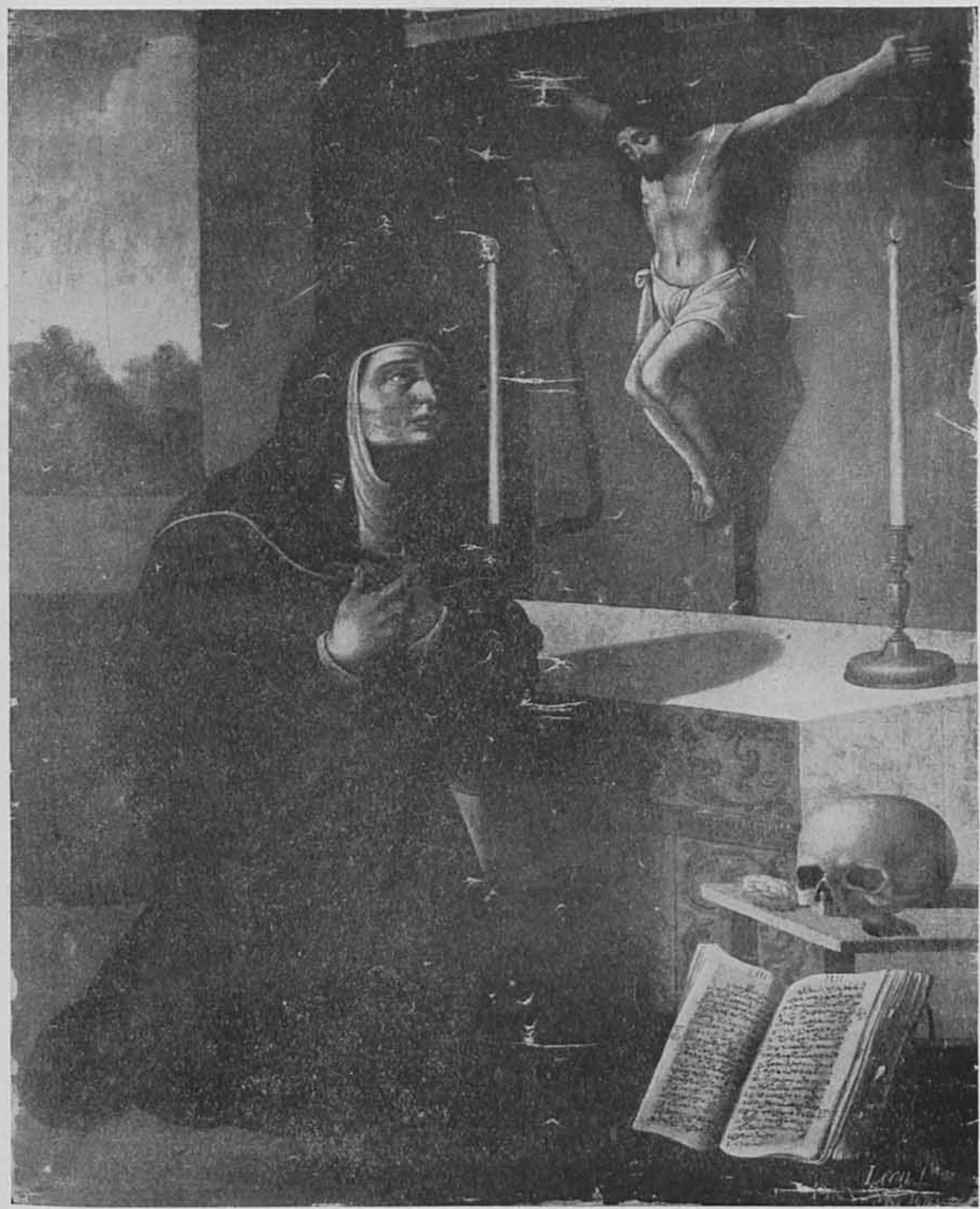

7. Francisco de León.-Santa Rita de Casia. $1.10 \times 1.63$ m. Zacatecas 